\title{
Determination of the anxiety and the needs of family members of critical care patients in emergency departments
}

\author{
(1) Ayla Demirtaş ${ }^{1}$, (1) Gülten Güvenç ${ }^{1}$, (1) Özlem Aslan², (1) Emine Öksüz', (1) Ayşe Kılıç Uçar ${ }^{3}$ \\ 1 University of Health Sciences Turkey, Gülhane School of Nursing, Ankara, Turkey \\ 2Ufuk University, School of Nursing, Ankara, Turkey \\ 3/stanbul Bilim University, Florence Nightingale School of Nursing, Istanbul, Turkey
}

\section{Date submitted:}

05.04.2020

Date accepted:

17.04.2020

Online publication date:

15.12.2020

\section{Corresponding Author:}

Ayla Demirtaş PhD, RN, Assistant

Professor, University of Health

Sciences Turkey, Gülhane Faculty of

Nursing, Ankara, Turkey

ayserdemir@yahoo.com

ORCID:

orcid.org/0000-0001-7952-770X

Presented in: The abstract of the manuscript represented as a oral at the $3^{\text {th }}$ Health Sciences Congress, on November 29, December 01, 2018, Ankara, Turkey

Keywords: Anxiety, emergency department, family members

\begin{abstract}
Aims: It is very important to find ways to meet the needs of patients' family members and to control their anxiety. This study aims to identify the needs and anxiety levels of family members of critically-ill adult patients in emergency departments (ED).

Methods: This descriptive study was conducted in the adult ED of a training and research hospital in Turkey. In order to collect data, we conducted face-to-face interviews with family members of critically-ill patients. The "Critical Care Family Needs Inventory-Emergency Department" (CCFNI-ED) and the "Spielberger State Trait Anxiety Inventory-State Scale" (STAI-S) were also used to identify the needs and the anxiety levels of the family members.

Results: The average age of the participants was $40.81 \pm 13.32$ years. Of the participants $(n=172)$, $61.6 \%(n=106)$ were female. CCFNI-ED results showed that eight of the ten needs expressed by family members were related to communication. Overall anxiety level of the family members was $49.67 \%$. Additionally, a statistically significant correlation was found between being female and STAI-S scores $(t=2.41, p=0.01) .18 .6 \%$ of family members expressed that their needs were unmet, while $29.1 \%$ of the participants stated that their needs were met.

Conclusions: This study found no significant correlations between the scores obtained from STAI-S and CCFNI-ED. However, a statistically significant correlation was found between being female and STAI-S scores of relatives. Health professionals should take the higher anxiety levels of female family members into consideration, and they should pay attention to the needs of patients' relatives in order to manage their anxiety.
\end{abstract}

\section{Introduction}

Emergency departments (ED) are the environments that require skilled professionals to take care of critical patients $(1,2)$. Patients and their family members face various problems in the EDs, both in Turkey and over the world. Essential elements of holistic patient care include considering family members as a part of critical care and engaging in attempts to protect and maintain the functions of patients and their families (3). Furthermore, identifying the needs of critically ill patients' family members will help ED professionals focus on and meet the urgent needs of the families. Understanding the feelings of patients' families and identifying their needs may improve health care and communication. In addition, identifying the needs of family members may increase families' confidence in health professionals and prevent negative and even aggressive behaviors $(4,5)$.

EDs are traumatic environments that may create anxiety for patients and their families. The health problems of a family member influence the entire family. Patients' families may consider admittance to the ED as a crisis (1). Moreover, family members who wait for long hours in EDs face uncertainty, which in turn creates stress and anxiety (6). Evaluating the needs of patients and their families and attempting to meet their needs will not only reduce anxiety and stress of family members but also improve patient satisfaction and quality of healthcare $(7,8)$. 
Frequently, emergency professionals must turn their attention to saving the patient's life and decreasing the physical effects of trauma (6). Consequently, communication with the patient's family members, identification of their needs, and attempts to decrease their anxiety may fade into the background. Health professionals' attitudes, long waiting times to receive treatment, and remaining uninformed about diagnosis and treatment are among the main problems that patients and family members complain about in EDs (9). These problems may result in conflicts between health professionals and family members. Therefore, it is very important to identify family members' needs, to attempt to meet stated needs, and to control their anxiety (10). However, the number of studies on identifying the anxiety and needs of patients' family members is limited. This study aims to contribute to the literature by identifying the anxiety and the importance order of the needs of family members of criticallycare adult patients in EDs.

\section{Methods}

\section{Design}

This study was conducted in the ED of a training and research hospital in Turkey between May 2016 and November 2017. This ED experiences more than 100,000 visits per year and is composed of two units: the triage area and general care. The clinical status of the outpatients is first evaluated by health professionals in the triage unit using the Emergency Severity Index, and the patients are directed to the appropriate physicians from the triage unit. The triage unit has four emergency treatment rooms, one blood sample collection room, one medical dressing room, one electrocardiogram room, and one orthopedic casting room. One emergency medicine specialist and two practicing physicians work in the ED. The general care unit of the ED has three trauma and resuscitation rooms and 10 monitoredobservation rooms, which are allocated to critically-ill patients. Three emergency physicians provide health care services in the general care unit.

\section{Participants and Procedure}

This descriptive study was conducted with 172 family members of critically-ill patients, all of whom had accompanied patients to the ED. Family members were informed both verbally and in writing about that participation in the research was voluntary, they could withdraw from the study whenever they wanted, and their decision to withdraw from the study would have no impact upon the healthcare received by their patient relative. After their consent was obtained, family members were interviewed in a room in the ED at a time suitable for the relatives. Data collection lasted about 8-10 minutes for each participant Given the fact that families' perceived needs could change over time, interviews took place between the first 30 minutes and the first 24 hours after the patient was admitted to ED (4).
Family members over the age of 18 years, who accompanied the patient to the ED, were present in the ED for more than 30 minutes, and voluntarily agreed to participate, were included in the study.

\section{Data Collection}

We used the "Data Collection Form", "Critical Care Family Needs Inventory-Emergency Department" (CCFNI-ED), and "Spielberger State Trait Anxiety Inventory-State Scale" (STAI-S) for our data collection.

Data Collection Form: Data collection form was prepared by the researchers based on relevant literature and included questions on sociodemographic characteristics of patients and family members (age, gender, profession, educational status, marital status, etc.), relationship with the patient, hour of arrival at the ED, and length of stay in the ED.

CCFNI-ED: The CCFNI was developed by Redley and Beanland (2004) (3) and consists of 40 statements on family needs. Participants rate the importance of the 40 items using a four-point Likert type scale. The scale has four subscales: communication with family members, family member participation in ED care, organizational comfort, and family member support process. Reliability and validity of the Turkish version of the CCFNI-ED were tested by Sucu Dag et al. (11), who found that the Cronbach's alpha coefficient of the Turkish version of the CCFNI-ED was 0.91. We calculated a Cronbach's alpha coefficient of 0.90 for this study.

STAI-S: This scale was developed by Spielberger et al. (12) in order to determine a transitory emotional state at a certain time and under certain conditions; it has 20 items. Participants rate their emotional state using a four-point Likert type scale. Reliability and validity of the Turkish version of the STAI were calculated by Oner and Le Compte (13). Cronbach's alpha coefficient for our study is 0.64 .

\section{Ethical Consideration}

We obtained permission from the Scientific Research and Publication Ethics Board of the university at which the research was conducted (April 5, 2016; no: 50687469-1491-286-16/1648931). Participants were informed about the scope of the study and the confidentiality of their personal information, and their verbal and written consent was obtained.

\section{Statistical Analysis}

We used Statistical Package for the Social Sciences version 21 statistical software for data and statistical analysis. In terms of descriptive analysis, we used number and percentage for numerical data, and average \pm standard deviation for measurable data. The chi-square, one-way ANOVA, and Spearman correlation tests were used for comparative statistical analysis; $p<0.05$ indicated a statistically significant difference. 


\section{Results}

The average age of the family members coming to the ED with their critically ill patients was $40.81 \pm 13.32$ years. $61.6 \%$ of the participants were female $(n=106), 41.9 \%$ were high school graduates $(n=72), 72.7 \%$ were married $(n=125)$, and $55.2 \%$ were employed $(n=95)$. In addition, $96.5 \%$ of the participants had health insurance $(n=166), 28.5 \%$ of the participants had one or more children $(n=49), 80.8 \%$ arrived at the ED with their critically-ill patients $(n=139)$, and $52.3 \%$ expressed that their needs were met well in the ED $(n=90)$ (Table 1).

Table 2 shows STAI-S and CCFNI-ED scores of the participants. The average STAI-S score of participants was $49.67 \pm 0.67$, while the average CCFNI-ED score was $3.55 \pm 0.43$.

In Table 3, there are sub-dimensions and mean scores of the CCFNI-ED scale. 1st sub-dimension of CCFNI-ED is "Communication with family members". The average score obtained for the "Communication with family members" subdimension of the participants is $3.62 \pm 0.43$. The item "To know about the expected outcome" yielded the highest average score in this subscale $(3.98 \pm 0.13)$ whereas the item "To have a staff member with you while visiting your relative" received the lowest score (3.25 \pm 1.00$)$.

The second sub-dimension of CCFNI-ED is "family member participation in ED care". The score of "Family member participation in ED care" subscale of the CCFNI-ED was $3.43 \pm 0.57$. The item "to see your relative as soon as possible" yielded the highest average score in this subscale $(3.65 \pm 0.75)$, whereas the item "to be told about religious services" received the lowest score $(3.23 \pm 1.02)$.

The $3^{\text {rd }}$ sub-dimension of CCFNI-ED is "Organizational comforts". The average score obtained for the "organizational comforts" subscale was $3.60 \pm 0.53$. The item with the highest average score in this subscale was "to be treated as individual" (3.70 \pm 0.70$)$, whereas the item "to have questions answered honestly" received the lowest score (3.54 \pm 0.84$)$.

The fourth sub-dimension of CCFNI-ED, which is the last dimension, is "Family member support processes". The average score of the "family member support processes" subscale was $3.56 \pm 0.51$. The item "to have a person to care for the family" received the highest score $(3.68 \pm 0.67)$, whereas the item "to find out the condition of your relative before being asked to sign papers" received the lowest score $(3.42 \pm 0.91)$ (Table 3).

We found no statistically significant correlations between the descriptive characteristics of the participants and CCFNIED scores ( $p>0.05$ ) (Table 4). Although we found a statistically significant correlation between gender and STAI-S scores (females got high scores in STAI-S $(t=2.41, p=0.01)$, no statistically significant correlation was found between the other descriptive characteristics of the participants and STAI-S scores.

\section{Discussion}

This study analyzed the anxiety levels and needs of family members of critically-ill adult patients in the ED. In our study, $80.8 \%$ of the participants arrived at the ED with their critically ill relatives. Sucu et al.'s (7) study on the family members of 353 critical-care patients found that $82.2 \%(n=321)$ of the participants had accompanied their patients. Similarly, another study conducted by Sucu Dag et al. (11) on the relatives of 400 critical-care patients found that $80.1 \%(n=322)$ of the

\begin{tabular}{|c|c|c|}
\hline \multirow{2}{*}{$\begin{array}{l}\text { Age (mean } \pm \text { SD) years } \\
\text { Gender }\end{array}$} & \multicolumn{2}{|c|}{$40.81 \pm 13.32$} \\
\hline & $\mathbf{n}$ & $\%$ \\
\hline Female & 106 & 61.6 \\
\hline Male & 66 & 38.4 \\
\hline \multicolumn{3}{|l|}{ Educational level } \\
\hline Elementary & 22 & 12.8 \\
\hline Secondary & 23 & 13.4 \\
\hline High school & 72 & 41.9 \\
\hline University and above & 55 & 32.0 \\
\hline \multicolumn{3}{|l|}{ Marital status } \\
\hline Married & 125 & 72.7 \\
\hline Single & 47 & 27.3 \\
\hline \multicolumn{3}{|l|}{ Employment status } \\
\hline Employed & 95 & 55.2 \\
\hline Unemployed & 77 & 44.8 \\
\hline \multicolumn{3}{|l|}{ Proximity status } \\
\hline Partner & 30 & 17.4 \\
\hline Child & 49 & 28.5 \\
\hline Mother-father & 46 & 26.7 \\
\hline Brother & 17 & 9.9 \\
\hline Other relatives & 16 & 9.3 \\
\hline Friends & 14 & 8.1 \\
\hline \multicolumn{3}{|c|}{ Time for relatives to come to the ED } \\
\hline With patient & 139 & 80.8 \\
\hline After the patient & 33 & 19.2 \\
\hline \multicolumn{3}{|c|}{ Health assurance of the patient } \\
\hline Yes & 166 & 96.5 \\
\hline None & 6 & 3.5 \\
\hline \multicolumn{3}{|l|}{ Meeting the needs } \\
\hline None & 5 & 2.9 \\
\hline Moderate & 27 & 15.7 \\
\hline Well & 90 & 52.3 \\
\hline Completely & 50 & 29.1 \\
\hline
\end{tabular}


participants arrived at the ED with their critically-ill relatives. Yildirim and Ozlu (14) found that nearly all patients (91.6\%) were accompanied by their relatives to the hospital. It will be better for health care professionals if family members accompany their critically-ill relatives, in order to receive information about the patient and their illnesses.

The analysis of the relationships between the family members and the patients showed that $28.7 \%$ of the participants were children of the patients, $26.7 \%$ were parents of the patients, and $17.4 \%$ were spouses of the patients. Hsiao et al. (8) found that critically-ill patients were mostly accompanied by their children and others, whereas Sucu et al. (2009) (7) found that family members that accompanied critically-ill patients to the EDs were mostly spouses. In our study, accompanying spouses ranked third. Parallel to our findings, the study by Yildirim and Ozlu (14) showed that critically-ill patients were mostly accompanied by their children (14). We can state that, in Turkey, critically-ill patients admitted to the ED are mostly accompanied by their first-degree relative(s).

In terms of time spent in the ED, our study found that $26.2 \%$ of the patients stayed for about 1-2 hours. In comparison, Redley and Beanland (3) found that family members of the critically-ill patients spent between 15 minutes and 36 hours (5.5 hours on average).

Al et al.'s (15) study on patients and families in the ED found no statistically significant relationship between relatives' satisfaction with the EDs and education, age, or transfer type of the patient. Similarly, we did not find any statistically significant relationship between these parameters and the order of importance of family members' needs.

We found that the needs of family members were not completely met in the ED. $18.6 \%$ of the participants expressed that their needs were unmet, whereas $29.1 \%$ stated that their needs were completely met. Satisfaction of patients and their relatives is frequently used as an indicator of quality of healthcare services in EDs. Satisfaction will increase when the needs of family members are met. So, healthcare professionals should be aware of the needs of family members. Botes and
Langley's (16) study on family members in an ED found that although the communication subscale of the CCFNI was ranked as highly important, satisfaction with communication was low. Moreover, Bulut (9) found that informing family members increased their satisfaction.

Regarding the subscales of the CCFNI-ED, participants in this study ranked communication needs highest, followed by family member support processes, organizational comfort, and family member participation in ED care. In the study of Sucu et al. (7), the communication subscale ranked the second in importance, whereas family member participation ranked the first. However, family members in Hsiao et al. (8) ranked communication needs highest, followed by family member participation, support, and comfort. Yildirim and Ozlu (14) found that the most important need identified by the family members was communication, whereas the least important need was comfort. Finally, Botes and Langley (16) found that communication ranked the second in importance. Based on these studies, we can suggest that the 'organizational comfort' and 'family member support processes' subscales of the CCFNI-ED are relatively less important for patients' relatives. This indicates that patients' relatives place less importance on their own needs than on the needs of the critically-ill patients.

Item scores related to the needs of the family members in our study were similar to previous findings. All four items that had a score above 3.89 belonged to the 'communication with family members' subscale. Five of the items that had a score above 3.79 were related to the communication need: "to know about the expected outcome" (3.98), "to be given directions regarding what to do at the bedside" (3.91), "to know why things were done for your relative" (3.90), "to be spared distressing details about your relative's illness or injury" (3.90), and "to see what was happening to your relative" (3.81) (Table 2). These findings differ from the findings of Sucu and Sucu Dag et al. $(7,11)$, Yildirim and Ozlu (14), and Hsiao et al. (8) in terms of the order of importance.

Patients' family members go through a unique, intense, and emotional experience in the ED (2). The chaotic structure of EDs often results in difficulties for health professionals,

\begin{tabular}{|c|c|c|c|c|}
\hline CCFNI sub-dimensions and STAI-S & Mean \pm SD & Lower score & Upper score & Scale's ranges \\
\hline \multicolumn{5}{|l|}{ CCFNI } \\
\hline Communication with family members & $3.62 \pm 0.43$ & 2.20 & 4.00 & $1-4$ \\
\hline Family member participation in ED care & $3.43 \pm 0.57$ & 1.50 & 4.00 & $1-4$ \\
\hline Organizational comforts & $3.60 \pm 0.53$ & 1.56 & 4.00 & $1-4$ \\
\hline Family member support processes & $3.56 \pm 0.51$ & 1.57 & 4.00 & $1-4$ \\
\hline CCFNI total & $3.55 \pm 0.43$ & 1.94 & 4.00 & $1-4$ \\
\hline STAI-S & $49.67 \pm 0.67$ & 48.50 & 51.50 & $20-80$ \\
\hline
\end{tabular}


Table 3. CCFNI-ED scores of the participants

\section{CCFNI-ED Items}

\section{Communication with family members}

9. To know why procedures were done for your relative

10. To be spared distressing details about your relative's illness or injury

12. To talk to a nurse

13. To know about the expertise of staff caring for your relative

14. To know about the expected outcome

18. To stay out of the way during your relative's care

20. To have explanations about the treatment area before going in to see your relative for the first time

21. To have a staff member with you while visiting your relative

22. To see what was happening to your relative

24. To be given directions regarding what to do at the bedside

Family member participation in ED care

4. To have friends and relatives with you while in the emergency department

19. To see your relative as soon as possible

23. To be with your relative at any time

25. To feel helpful to your relative's care

26. To be included when decisions are made

27. To have time alone with your relative

28. To feel accepted by hospital staff

32. To be encouraged to express emotions

33. To be reassured as to what normal emotional responses should be

34. To share emotions with staff

36. To be told about religious services

37. To have food and refreshments nearby

38. To have a telephone in or near the waiting room

39. To have toilet facilities nearby

\section{Organizational comforts}

11. To talk to a doctor

15. To have questions answered honestly

16. To be told about transfer plans while they are being mad

17. To be assured that the best care possible has been given to your relative

29. To be treated as an individual

30. To feel hospital staff care about your relative

31 . To be assured of the comfort of your relative

35. To feel there is hope

40. To be able to contact staff at a later date to ask questions

Family member support processes

1. To have a doctor or nurse meet you on arrival at the hospital

2. To have a person to care for the family

3. To find out the condition of your relative before being asked to sign papers

5. To have a private place to wait

6. To have explanations given in understandable terms

7. To be kept updated frequently

8. To know all the specific facts concerning your relative's progress

Total

CCFNI-ED: Critical Care Family Needs Inventory-Emergency Department, SD: Standard deviation, Min: Minimum, Max: Maximum

\begin{tabular}{|llll|}
\hline Mean & SD & Min & Max \\
\hline 3.62 & $\mathbf{0 . 4 3}$ & $\mathbf{2 . 2 0}$ & $\mathbf{4 . 0}$ \\
\hline 3.90 & 0.36 & 2.00 & 4.00 \\
\hline 3.90 & 0.36 & 1.00 & 4.00 \\
\hline 3.67 & 0.70 & 1.00 & 4.00 \\
\hline 3.27 & 0.92 & 1.00 & 4.00 \\
\hline 3.98 & 0.13 & 3.00 & 4.00 \\
\hline 3.24 & 0.88 & 1.00 & 4.00 \\
\hline 3.60 & 0.80 & 1.00 & 4.00 \\
\hline 3.25 & 1.00 & 1.00 & 4.00 \\
\hline 3.81 & 0.51 & 1.00 & 4.00 \\
\hline 3.91 & 0.28 & 3.00 & 4.00 \\
\hline 3.43 & $\mathbf{0 . 5 7}$ & 1.50 & 4.00 \\
\hline 3.19 & 0.90 & 1.00 & 4.00 \\
\hline 3.65 & 0.75 & 1.00 & 4.00 \\
\hline 3.56 & 0.74 & 1.00 & 4.00 \\
\hline 3.63 & 0.65 & 1.00 & 4.00 \\
\hline 3.59 & 0.79 & 1.00 & 4.00 \\
\hline 3.48 & 0.81 & 1.00 & 4.00 \\
\hline 3.53 & 0.83 & 1.00 & 4.00 \\
\hline 3.36 & 0.95 & 1.00 & 4.00 \\
\hline 3.44 & 0.84 & 1.00 & 4.00 \\
\hline 3.09 & 1.05 & 1.00 & 4.00 \\
\hline 3.23 & 1.02 & 1.00 & 4.00 \\
\hline 3.35 & 0.89 & 1.00 & 4.00 \\
\hline 3.38 & 0.82 & 1.00 & 4.00 \\
\hline 3.63 & 0.68 & 1.00 & 4.00 \\
\hline 3.60 & $\mathbf{0 . 5 3}$ & $\mathbf{1 . 5 6}$ & 4.00 \\
\hline 3.57 & 0.80 & 1.00 & 4.00 \\
\hline 3.54 & 0.84 & 1.00 & 4.00 \\
\hline 3.61 & 0.71 & 1.00 & 4.00 \\
\hline 3.60 & 0.81 & 1.00 & 4.00 \\
\hline 3.70 & 0.70 & 1.00 & 4.00 \\
\hline 3.69 & 0.72 & 1.00 & 4.00 \\
\hline 3.55 & 0.84 & 1.00 & 4.00 \\
\hline 3.56 & 0.80 & 1.00 & 4.00 \\
\hline 3.59 & 0.75 & 1.00 & 4.00 \\
\hline 3.56 & $\mathbf{0 . 5 1}$ & $\mathbf{1 . 5 7}$ & 4.00 \\
\hline 3.57 & 0.85 & 1.00 & 4.00 \\
\hline 3.68 & 0.67 & 1.00 & 4.00 \\
\hline 3.42 & 0.91 & 1.00 & 4.00 \\
\hline 3.45 & 0.83 & 1.00 & 4.00 \\
\hline 3.60 & 0.76 & 1.00 & 4.00 \\
\hline 3.60 & 0.80 & 1.00 & 4.00 \\
\hline 3.57 & 0.65 & 1.00 & 4.00 \\
\hline 3.55 & $\mathbf{0 . 4 3}$ & $\mathbf{1 . 9 4}$ & 4.00 \\
\hline & & & \\
\hline
\end{tabular}


including communication with the patient (17). This may result in ED health professionals being unable to provide important medical information to patients and their families (18). Hsiao et al. (8) found that communication with family members was the most important need not only for family members but also for emergency nurses.

Health professionals should engage in active listening skills when communicating with the patients and their families. Communication in EDs may be verbal or nonverbal, and the communication method depends on the judgment of the emergency professionals. Health professionals working in EDs should maintain effective communication with patients and their families in order to improve the efficiency of healthcare (19). Shorofi et al.'s (20) study on family members found that the most important item of the CCFNI-ED scale was "to have questions answered honestly". In this sense, studies on critically-ill patients show the importance of communication.

EDs are loud and crowded, which may cause anxiety for patients and their families $(21,22)$. However, unexpectedly, our study did not find any statistically significant relationship

\begin{tabular}{|c|c|c|c|c|}
\hline \multirow[t]{2}{*}{ Characteristics of participants } & \multicolumn{2}{|l|}{ CCFNI } & \multicolumn{2}{|l|}{ STAI-S } \\
\hline & Mean \pm SD & Analysis & Mean \pm SD & Analysis \\
\hline \multicolumn{5}{|l|}{ Gender } \\
\hline Female & $3.60 \pm 0.36$ & \multirow{2}{*}{$\begin{array}{l}t=1.79 \\
p=0.07\end{array}$} & $49.57 \pm 0.63$ & \multirow{2}{*}{$\begin{array}{l}t=2.41 \\
p=0.01\end{array}$} \\
\hline Male & $3.47 \pm 0.51$ & & $49.83 \pm 0.71$ & \\
\hline \multicolumn{5}{|l|}{ Educational level } \\
\hline Elementary & $3.55 \pm 0.43$ & \multirow{4}{*}{$\begin{array}{l}F=1.14 \\
p=0.33\end{array}$} & $49.61 \pm 0.43$ & \multirow{4}{*}{$\begin{array}{l}F=0.28 \\
p=0.83\end{array}$} \\
\hline Secondary & $3.56 \pm 0.48$ & & $49.79 \pm 0.92$ & \\
\hline High school & $3.56 \pm 0.43$ & & $49.67 \pm 0.63$ & \\
\hline University and above & $3.59 \pm 0.38$ & & $49.65 \pm 0.70$ & \\
\hline \multicolumn{5}{|l|}{ Marital status } \\
\hline Married & $3.58 \pm 0.41$ & \multirow{2}{*}{$\begin{array}{l}t=0.13 \\
p=1.51\end{array}$} & $49.70 \pm 0.69$ & \multirow{2}{*}{$\begin{array}{l}t=0.90 \\
p=0.36\end{array}$} \\
\hline Single & $3.47 \pm 0.54$ & & $49.59 \pm 0.62$ & \\
\hline \multicolumn{5}{|l|}{ Employment status } \\
\hline Employed & $3.51 \pm 0.44$ & \multirow{2}{*}{$\begin{array}{l}t=1.55 \\
p=0.42\end{array}$} & $49.67 \pm 0.69$ & \multirow{2}{*}{$\begin{array}{l}t=0.90 \\
p=0.36\end{array}$} \\
\hline Unemployed & $3.61 \pm 0.41$ & & $49.67 \pm 0.64$ & \\
\hline \multicolumn{5}{|l|}{ Proximity status } \\
\hline Partner & $3.52 \pm 0.47$ & \multirow{6}{*}{$\begin{array}{l}F=0.98 \\
p=0.42\end{array}$} & $49.58 \pm 0.78$ & \multirow{6}{*}{$\begin{array}{l}F=0.57 \\
p=0.72\end{array}$} \\
\hline Child & $3.58 \pm 0.39$ & & $49.59 \pm 0.59$ & \\
\hline Mother-father & $3.60 \pm 0.39$ & & $49.73 \pm 0.79$ & \\
\hline Brother & $3.60 \pm 0.47$ & & $49.78 \pm 0.59$ & \\
\hline Other relatives & $3.34 \pm 0.58$ & & $49.84 \pm 0.51$ & \\
\hline Friends & $3.51 \pm 0.35$ & & $49.65 \pm 0.59$ & \\
\hline \multicolumn{5}{|c|}{ Time for relatives to come to the ED } \\
\hline With patient & $3.55 \pm 0.45$ & \multirow{2}{*}{$\begin{array}{l}t=0.44 \\
p=0.65\end{array}$} & $49.75 \pm 0.69$ & \multirow{2}{*}{$\begin{array}{l}t=1.52 \\
p=0.13\end{array}$} \\
\hline After the patient & $3.46 \pm 0.22$ & & $49.32 \pm 0.53$ & \\
\hline \multicolumn{5}{|l|}{ Health assurance of the patient } \\
\hline Yes & $3.56 \pm 0.42$ & \multirow{2}{*}{$\begin{array}{l}t=1.86 \\
p=0.064\end{array}$} & $49.67 \pm 0.68$ & \multirow{2}{*}{$\begin{array}{l}t=0.29 \\
p=0.76\end{array}$} \\
\hline None & $3.23 \pm 0.57$ & & $49.58 \pm 0.61$ & \\
\hline \multicolumn{5}{|l|}{ Meeting the needs } \\
\hline None & $3.66 \pm 0.23$ & \multirow{4}{*}{$\begin{array}{l}F=0.17 \\
p=0.94\end{array}$} & $49.65 \pm 0.67$ & \multirow{4}{*}{$\begin{array}{l}F=5.79 \\
p=0.09\end{array}$} \\
\hline Moderate & $3.58 \pm 0.43$ & & $49.31 \pm 0.62$ & \\
\hline Well & $3.55 \pm 0.40$ & & $49.63 \pm 0.62$ & \\
\hline Completely & $3.53 \pm 0.43$ & & $49.97 \pm 0.70$ & \\
\hline
\end{tabular}


between STAI-S and CCFNI-ED scores. The only statistically significant relationship was between being female and STAI-S scores $(t=2.411, p=0.017)$. Dark et al.'s (2018) (23) study, which analyzed 1,213 ED visits with a discharge diagnosis of anxiety, found that $63.1 \%$ of the patients were female, whereas $36.9 \%$ were male. For the reason that anxiety disorder is more common among women, we may conclude that female patients and relatives may need special attention from health professionals. Additionally, various studies have assessed the extent to which music may be used to decrease anxiety of patients and their families. For example, a randomized pilot study by Belland et al. (18) found that listening to music reduced anxiety among older adults in the ED. Similarly, Kilic et al. (21) found that music therapy in the ED positively impacted patients' pain levels and anxiety. Based on these studies, we may suggest music therapy in EDs to reduce anxiety of both patients and family members.

Some patients demand to have their family members present in case of a health problem, and the presence of family members may reduce patient anxiety (24). Additionally, providing family-oriented education on communication skills may not only help family members but also reduce anxiety, depression, and stress in patients (14). However, this may not always occur. Batista et al. (2) found that the presence of family members in EDs increased family anxiety and health professional stress levels. The average STAI-S score of the participants in this study reflects a medium anxiety level (mean=49.67).

However, the recent guidelines of the American Heart Association and the European Resuscitation Council state that family members can be present in advanced health situations whenever possible (2). Paavilainen et al. (4) also suggest encouraging family presence in EDs. One advantage of family presence in EDs stems from the fact that family members may provide clinical information about the patient to the health professionals (1). Furthermore, being able to be with the patient helps family members adapt to the unexpected, critical situation. Psychological support to patient families, who experience intensive stress and sorrow, may reduce their anxiety and fears (14). In sum, deciding whether the presence of family members is good or bad is a hard decision; it may vary according to cultural values and perspectives (19).

Health professionals that are responsible for criticallyill patients should provide care that integrates knowledge, skills, experience, and attitudes, all of which are needed to meet the needs of patients and their families (25). Emergency professionals that are aware of patients' and families' needs may be able to meet these needs and thus reduce anxiety; this, in turn, may prevent possible confrontations between health professionals and family members.

Our study had some limitations, such as generalization difficulties because this study was conducted in only one ED. In addition, our working group does not reflect the general situation in the country. The stress levels of the patient relatives may be higher in other hospitals which are not education and research hospitals.

\section{Clinical Implications for Emergency Nursing}

Relatives of the patients often feel stressed and worried about the uncertainty of emergency services. These concerns can sometimes come to a dimension that goes back to conflicts with health personnel. It can be difficult for health personnel to manage uncertainty and concern. Health personnel should cooperate with the patient's relative to manage the case effectively and effectively. Otherwise, the situation may become complicated and problems may arise in medical and psychosocial issues. It is important for health personnel to understand the needs and concerns of their relatives. Thus, they can provide them with safe and effective emergency service intervention.

\section{Conclusion}

This study found no statistically significant relationship between the STAI-S scores of patients' family members and their CCFNI-ED scores. However, we found a statistically significant relationship between being female and STAI-S scores. The most important need identified by family members was communication, followed by family member support, comfort, and family member participation in ED care. Based on these findings, we suggest that the needs of the family members of critically-ill patients should be identified and met within the context of healthy communication. Emergency professionals should consider the possibility that the anxiety levels of female relatives may be higher, and these professionals should determine and meet the needs of family members in order to control their anxiety.

\section{Ethics}

Ethics Committee Approval: We obtained permission from the Scientific Research and Publication Ethics Board of the university at which the research was conducted (April 5, 2016; no: 50687469-1491-286-16/1648-931).

Informed Consent: Participants were informed about the scope of the study and the confidentiality of their personal information, and their verbal and written consent was obtained.

Peer-review: Externally peer-reviewed.

\section{Authorship Contributions}

Surgical and Medical Practices: A.D., Concept: A.D., G.G., Design: A.D., G.G., Data Collection or Processing: A.D., A.K.U., Analysis or Interpretation: E.Ö., Literature Search: A.D., Ö.A., Writing: A.D. 
Conflict of Interest: No conflict of interest was declared by the authors.

Financial Disclosure: The authors declared that this study received no financial support.

\section{References}

1. Brysiewicz P, Emmamally W. Focusing on families in the emergency department. International Emergency Nursing. 2017;30:1-2.

2. Batista MJ, Vasconcelos $P$, Miranda $R$, et al. Family presence during emergency situations: the opinion of nurses in the adult emergency department. Revista de Enfermagem Referência Série. 2017;4:83-92.

3. Redley B, Beanland C. Revising the critical care family needs inventory for the emergency department. J Adv Nurs. 2004;45:95-104.

4. Paavilainen E, Salminen-Tuomaala M, Kurikka S, Paussu $P$. Experiences of counselling in the emergency department during the waiting period: importance of family participation. Journal of Clinical Nursing. 2009;18:2217-2224.

5. Innes K, Jackson D, Plummer V, Elliott D. Care of patients in emergency department waiting rooms an integrative review. J Adv Nurs. 2015;71:2702-2714.

6. Verharen L, Mintjes J, Kaljouw M, et al. Psychosocial Needs of Relatives of Trauma Patients. Health \& Social Work. 2015;40:233-238.

7. Sucu G, Cebeci F, Karazeybek E. Requirements and fulfillment of critical patient relatives in the emergency department. Ulus Travma Acil Cerrahi Derg. 2009;15:473481.

8. Hsiao PR, Redley B, Hsiao YC, et al. Family needs of critically ill patients in the emergency department. Int Emerg Nurs. 2017;30:3-8.

9. Bulut $\mathrm{H}$. The effect of informing patients and their relatives on satisfaction in emergency services. Ulus Travma Acil Cerrahi Derg. 2006;12:288-298.

10. Van-Keer RL, Deschepper R, Huyghens L, Bilsen J. Preventing Conflicts Between Nurses and Families of a Multi-ethnic Patient Population During Critical Medical Situations in a Hospital. J Transcult Nurs. 2020;31:250256.

11. Sucu Dag G, Dicle A, Firat MZ. Psychometric properties of the critical care family needs inventory-emergency department. Applied Nursing Research. 2017;3:113-120.

12. Spielberger CD, Gorsuch RI, Lushene RE. STAI Manual for the State-Trait Anxiety Inventory. Consulting Psychologist Press. 1970. Palo Alto, CA.
13. Oner N, Le Compte A. Süreksiz Durumluk/Sürekli Kaygı Envanteri El Kitabı. İstanbul: Boğaziçi Üniversitesi Yayınları. 1998;1-26.

14. Yildirim T, Ozlu ZK. Needs of critically III patients' relatives in emergency departments. Nurs Midwifery Stud. 2018;7:3338.

15. Al B, Yıldırım C, Bozkurt S, et al. Factors Affecting Patient Satisfaction in Emergency Department. JAEM. 2009;8:3944.

16. Botes ML, Langley $\mathrm{G}$. The needs of families accompanying injured patients into the emergency department in a tertiary hospital in Gauteng. Curationis. 2016;39:a1567.

17. Gozdzialski A, Schlutow M, Pittiglio L, et al. Patient And Family Education In The Emergency Department: How Nurses Can Help. J Emerg Nurs. 2012;38:293-295.

18. Belland L, Rivera-Reyes L, Hwang U. Using music to reduce anxiety amo1ng older adults in the emergency department: a randomized pilot study. J Integr Med. 2017;15:450-455.

19. Zani AV, Marcon SS, Tonete VLP, Parada CMGL, Communicative process in the emergency department between nursing staff and patients: social representations. Online Braz J Nurs. 2014;13:35-45.

20. Shorofi SA, Jannati Y, Moghaddam HR, Yazdani-Charati $\mathrm{J}$. Psychosocial needs of families of intensive care patients: Perceptions of nurses and families. Niger Med J. 2016;57:10-18.

21. Kilic SP, Karadag G, Oyucu S, et al. Effect of music on pain, anxiety, and patient satisfaction in patients who present to the emergency department in Turkey. JJJNS. 2015;12:4453.

22. Bandari R, Heravi-Karimooi M, Rejeh N, et al. Psychometric properties of the Persian version of the critical care family needs inventory. The Journal of Nursing Research. 2014;22:259-267.

23. Dark T, Rust G, Flynn HA, et al. Sociodemographic Influences of Emergency Department Care for Anxiety Disorders. J Behav Health Serv Res. 2018;45:593-604.

24. Islekdemir B, Kaya N. Effect of family presence on pain and anxiety during invasive nursing procedures in an emergency department: A randomized controlled experimental study. Int Emerg Nurs. 2016;24:39-45.

25. Kaplow R, Reed KD. The AACN Synergy Model for Patient Care: a nursing model as a Force of Magnetism. Nurs Econ. 2008;26:17-25. 